\title{
UNDERSTANDING OF WORK ROLL CORROSION AND OXIDATION IN A HOT STRIP MILL*
}

\author{
Sebastien Flament ${ }^{1}$ \\ Gisele Walmag ${ }^{2}$ \\ Mario Sinnaeve ${ }^{3}$
}

\begin{abstract}
More and more Hot Strip Mills are facing defects on their products that lead to a rejection of complete product batches by their customers. Several of those defects are induced by excessive work roll degradation. This paper is focussed on the understanding of work roll corrosion and oxidation mechanisms in a hot strip mill. Several laboratory trials (Hot rolling simulator, cyclic oxidation) have highlighted important factors influencing corrosion of work rolls as well as helping the understandings of oxidation of a work roll in the roll bite and along the roll circumference in a stand. The attention is focussed on several elements present in water used in HSM for direct roll cooling (e.g. chloride, bactericides, sulphates, phosphates...) and their effect on roll surface degradation. The second part of this paper is focused on the understanding of work roll oxidation along the roll circumference. The effects of roll composition, roll temperature, water composition and water temperature have been studied in order to understand the oxidation/corrosion mechanisms in a HSM.
\end{abstract}

Keywords: Work roll; Degradation; Cooling water; Corrosion; Oxidation; Hot rolling. 


\section{INTRODUCTION}

Work rolls in a hot rolling mill are subject to various environments and operating conditions depending on their position in the mill. The only common parameter to every work roll in a Hot Strip Mill is the water used for cooling. The influence of the cooling water composition on work roll degradation is very often underestimated in most of the hot strip mills worldwide.

This paper summarises research results done in the field of oxidation - corrosion and oxidation mechanisms of work rolls. Various water compositions have been simulated in lab in order to assess their influence on work roll oxidation - corrosion. The second part of this paper is focused on work roll oxidation. A dedicated trial has been developed in order to simulate the thermal cycling over a revolution of a work roll in a stand. The results of these simulations on a two-disk rolling simulator and on a cyclic oxidation device will be presented in this paper.

\section{RESULTS AND DISCUSSION}

\subsection{Work Roll Operating Conditions}

Depending on their position in the HSM, work rolls undergo various operating conditions which lead to the four known degradation mechanisms [1]:

- Thermal fatigue

- Oxidation / corrosion

- Wear

- Contact fatigue

These four concomitant and interrelated mechanisms will induce on the roll surface an increased roughness, peeling and even banding. The occurrence of each mechanism and relative importance compared to the others is dependent of the rolling conditions on one side and of the roll material on the other side.

Thermal fatigue concerns work rolls in contact with products at high temperature (rolls in roughing mill and rolls in the three to four first finishing stands). This mechanism depends on the roll material, i.e. of its thermal expansion coefficient, thermal conductivity, hot yield strength and low cycle fatigue (LCF) at room temperature. From the mill side, rolling conditions influences thermal fatigue through the product surface temperature, contact time, strip oxide thickness and roll cooling.

Roll oxidation is related to the roll material composition and heat treatment. It is also sensitive to the rolling parameters i.e. strip and roll temperature, roll cooling design, roll cooling water (composition, temperature) and to the presence of a back-up roll. Oxidation has been shown by Walmag et al. [1] to be induced by a combination of contact with the strip at high temperature and contact with chloride containing cooling water. Only this repeated cycling can explain the oxide thickness observed on industrial work rolls. Indeed, oxide thickness between 2 and $10 \mu \mathrm{m}$ have been observed after a rolling campaign (first finishing stands). Pure high temperature oxidation (laboratory studies) can only explain about a tenth of the oxide thickness observed on industrial work rolls.

Oxidation of the matrix surrounding the thermal fatigue and contact fatigue cracks is also very frequently observed. As this oxidation embrittles the material, we will call it corrosion. The presence of pits on work roll surface i.e. the removal of pieces of work material induced by local oxidation, is also called corrosion. 
Wear is influenced by different parameters [1,2,6] compared to the two first mechanisms. It depends on the friction coefficient, slip, rolling pressure, product mix, wear resistance of the roll material and the roll surface temperature.

Contact fatigue can only be observed on work rolls in a 4-high configuration (contact with a back-up roll). This phenomenon is mainly observed in the rear finishing stands. This degradation mechanism is induced by the contact pressure between the back-up roll (BUR) and the work roll (WR). Its severity is strongly related to the number of contacts and the work roll material itself.

The relative impact of each degradation mechanism depends thus on the stand and the work roll material itself.

\subsection{Cooling Water Compositions}

Cooling water should be considered as one of the key parameters of the rolling environment. It is usually a black box for most hot strip mills as its management is often sub-contracted. Cooling water is the only common parameter for every roll in a mill, and of primary importance for what concerns work roll degradation. The management of cooling water is a complex topic. Its temperature and composition may not only vary from one mill to another but also during the year. Table 1 illustrates this purpose for four European hot strip mills.

Table 1: Cooling water composition in four European hot strip mills

\begin{tabular}{|l|l|l|l|l|l|l|l|l|l|l|l|l|l|}
\hline & \multicolumn{3}{|l}{ HSM 1 } & \multicolumn{3}{l}{ HSM2 HSM3 } & \multicolumn{3}{l|}{ HSM4 } \\
\hline & Min & Avg & Max & Min & Avg & Max & Min & Avg & Max & Min & Avg & Max \\
\hline $\begin{array}{l}\text { Hardness } \\
\left({ }^{\circ}\right)\end{array}$ & 40 & 58 & 73 & 16 & 30 & 40 & 46 & 75 & 157 & 18.3 & 20.5 & 23.8 \\
\hline $\mathrm{Cl}^{-}(\mathrm{ppm})$ & 47 & 88 & 119 & 180 & 307 & 418 & 252 & 1220 & 3848 & 55.5 & 90.1 & 108 \\
\hline $\mathrm{pH}$ & 6.5 & 7.3 & 8 & 8.02 & 8.6 & 8.79 & 7.84 & 8.45 & 8.85 & 7.45 & 7.62 & 7.8 \\
\hline $\mathrm{X}(\mu \mathrm{S} / \mathrm{cm})$ & 490 & 690 & 954 & 893 & 1390 & 1770 & 1380 & 4385 & 11850 & 615 & 734 & 878 \\
\hline
\end{tabular}

\subsection{Work Roll Oxidation \& Corrosion}

The cumulated contact time between the work roll and the hot product depends on the position of the roll in a mill. In the first roughing stand of a continuous mill, the cumulated contact time (over a campaign length) of a work roll with the strip is less than one hour. This duration represents $0.2 \%$ of the roll life at high temperature.

In a finishing mill cumulated contact time between the work roll and the strip is lower compared to a roughing mill. The campaign durations are also shorter i.e. up to 3 weeks in a roughing mill compared to about 4 hours in a finishing mill. The cumulated contact time ranges from 75 seconds in the last finishing stand up to 240 seconds in the first finishing stand.

The conclusion of this observation is that the contact between the work roll and cooling water can reach up to 20 days in a continuous roughing mill, 3 up to 5 days for a reversible rougher roll and 4 hours in a finishing stand if roll cooling is always switched on.

In addition, compared to the roughing mill rolls, rolls in early finishing stands undergo a high temperature stage eight times longer over the campaign length (Table 2). 
Table 2: Comparison of cumulated contact times between roughing stands and finishing stands

\begin{tabular}{|l|l|l|l|l|}
\hline & Campaign length & $\begin{array}{l}\text { Duration in } \\
\text { contact with the } \\
\text { strip }\end{array}$ & $\begin{array}{l}\text { Duration in ing } \\
\text { contact with water }\end{array}$ & $\begin{array}{l}\% \text { at high } \\
\text { temperature }\end{array}$ \\
\hline RM reversible & $3-5$ days & No data & $\sim 3-5$ days & No data \\
\hline $\begin{array}{l}\text { RM continuous } \\
1^{\text {st }} \text { stand }\end{array}$ & $10-20$ days & $<60$ min & $\sim 10-20$ days & $0,2 \%$ \\
\hline F1 & 4 hours & 240 seconds & $\sim 4$ hours & $1,6 \%$ \\
\hline F7 & 4 hours & 75 seconds & $\sim 4$ hours & $0,5 \%$ \\
\hline
\end{tabular}

Cross section observations of scrapped work rolls highlighted the oxidation and corrosion phenomena (Figures 1a and 1b). In the first case, a homogeneous oxide layer is formed on the roll surface. We call this phenomenon oxidation. When oxidation of the matrix along thermal and contact fatigue cracks occurs, we call it corrosion. The second detrimental effect of corrosion is the removal of pieces of material.

Figure 1c illustrates the edge of a work roll barrel in a roughing stand after a campaign. During that period the cooling water contained a high chloride level. This zone of the work roll has never been in contact with a strip; the degradation illustrated is only due to corrosion (corrosion pits).

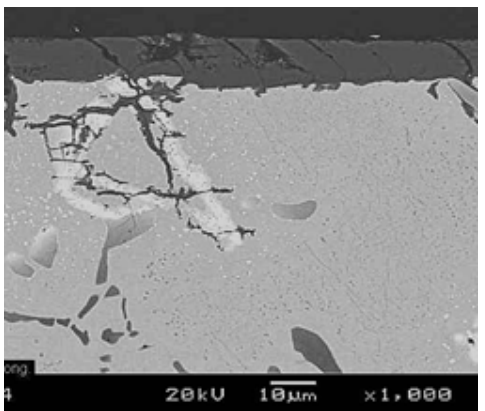

a)

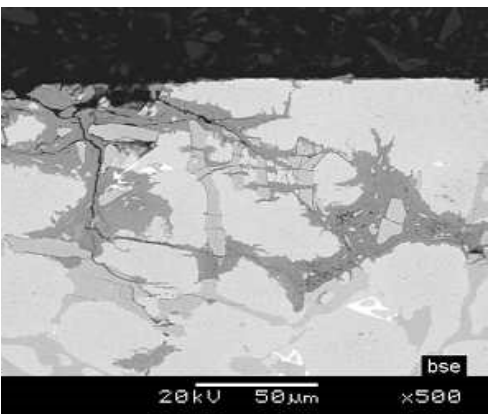

b)

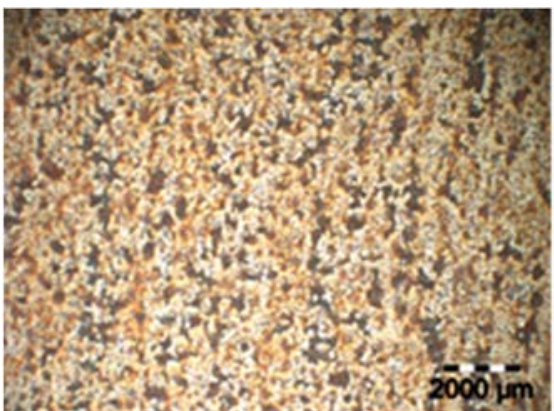

c)

Figure 1: Oxidation and corrosion of industrial scrapped work rolls: a) oxidation [1] (dark grey) b) corrosion of the matrix along cracks [1] c) Edge of a work roll barrel after a roughing campaign in a period with water containing high chloride level

Based on these observations, cooling water composition appears clearly as a key parameter to be taken into account in new roll developments and work roll degradation. It is the starting point of corrosion trials lead in CRM on work roll materials as well as oxidation-corrosion and oxidation trials.

\subsection{Experimental Details}

Investigations on work roll oxidation and corrosion have been performed on four work roll materials sampled out of industrial work rolls from Marichal Ketin. Their chemical compositions are mentioned in Table 3.

Table 3: Materials used for oxidation, corrosion and oxidation-corrosion trials

\begin{tabular}{|l|l|l|l|l|l|l|}
\hline Wt \% & $\mathbf{C}$ & $\mathbf{M n}$ & $\mathbf{S i}$ & $\mathbf{C r}$ & $\mathbf{M} \mathbf{r}+\mathbf{W}$ & $\mathbf{V + N b}$ \\
\hline HSS & $1.5-2.5$ & $0.5-1.5$ & $0.1-1.0$ & $4.0-6.0$ & $4.0-12.0$ & $4.0-8.0$ \\
\hline HiCr iron & $2.7-2.9$ & $0.9-1.1$ & $0.4-0.6$ & $16.0-19.0$ & $1.2-2.0$ & - \\
\hline HiCr steel & $1.2-1.5$ & $0.5-1.0$ & $0.3-0.6$ & $10.0-12.0$ & $2.0-5.0$ & $0.1-1.0$ \\
\hline ICDP & $3.2-3.5$ & $0.8-1.0$ & $0.9-1.1$ & $1.3-1.9$ & $0.3-0.5$ & - \\
\hline
\end{tabular}


Oxidation - corrosion of work rolls is simulated on a disks rolling simulator. This study has been carried out on $\mathrm{HSS}$, HiCr steel and $\mathrm{HiCr}$ iron materials. The discs rolling simulator [1] is constituted of two discs enabling to simulate the degradation of work rolls in hot rolling. The upper disc is heated by an induction coil enabling to preheat its surface up to $1100^{\circ} \mathrm{C}$. This upper disc simulates the hot product. The lower disk simulates the work roll. Four inserts of different roll grades are placed in this disk. The machine enables to test in a 2-high configuration the influence of several parameters on work roll degradation. This device has been used to study the influence of cooling water composition on work roll degradation; all other parameter being kept constant. Oxidation of work rolls has been studied on a dedicated cyclic oxidation device. The aim of this trial is to simulate the thermal cycling of a work roll in a rolling stand. The study has been performed on HSS and ICDP materials. A work roll sample is alternatively heated up in a furnace and cooled down in water. The furnace temperature and atmosphere can be controlled and adjusted as well as the water composition and temperature, the number of cycles to be performed and the durations of the high temperature and cooling stages. No humidity is added in the furnace atmosphere. Humidity in the high temperature phase is brought by the water present on the sample from the cooling phase.

\subsection{Results of Oxidation - Corrosion Tests on a Disk Rolling Simulator}

The analysis of the cooling water composition of several European hot strip mills ( Table 1) indicated a mean value of the chloride content around $350 \mathrm{ppm}$. This amount of chloride has been added in every cooling waters prepared for the degradation trials. Three chloride amounts have been tested as well as the additions of bactericide $(\mathrm{HOCl})$, sulphates (SO42-; used for $\mathrm{pH}$ adjustment), calcium (Ca2+; linked to water hardness) and phosphates (PO43- ; used in corrosion inhibitors). All these chemical compounds can be found in industrial waters at various concentrations. The $\mathrm{pH}$ of every solution has been adjusted between 8.0 and 8.1 to be in accordance with an industrial level. The degradation trials simulated the conditions of early finishing stands (strip temperature: $1050^{\circ} \mathrm{C}$, contact time: $70 \mathrm{~ms}$ in F1, rolling pressure: $220 \mathrm{MPa}$ ). 1920 cycles have been performed which represent about a tenth of an industrial finishing campaign. The evaluation of the degradation consists in a roughness measurement and a cross section examination. Based on these analyses, three parameters have been used to evaluate work roll degradation:

- The total height of the roughness profile (Rt)

- The corrosion factor which corresponds to the surface of the samples affected by corrosion

- The total crack length which is the sum of the length of all observed cracks The total roughness height of $\mathrm{HiCr}$ iron, $\mathrm{HSS}$ and $\mathrm{HiCr}$ steel evolution versus the water compositions are reported in Figure 2. Although work roll compositions vary in wide ranges, the impact of water quality on work roll surface degradation - oxidation results in similar trends for every tested material. 


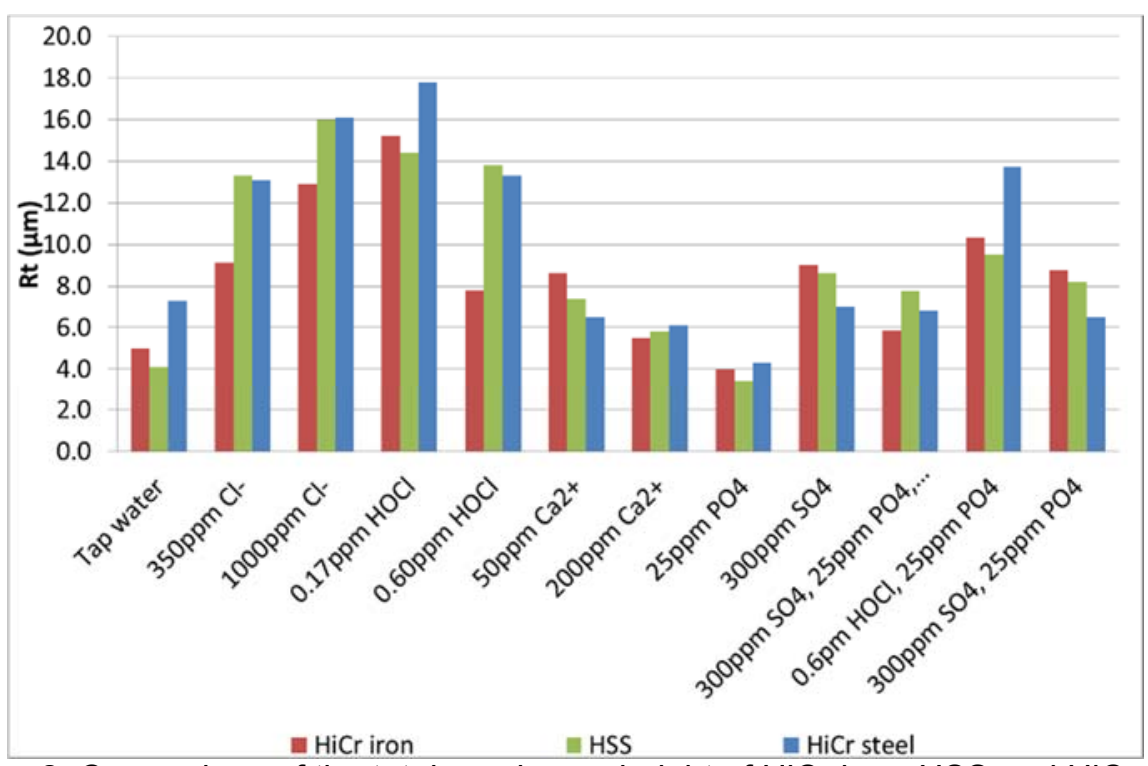

Figure 2: Comparison of the total roughness height of $\mathrm{HiCr}$ iron, $\mathrm{HSS}$ and $\mathrm{HiCr}$ steel

Roughness measurements are interesting for giving a first quick trend of surface degradation. This figure can however be misleading if the surface is covered with oxide. In this case, degradations under the oxide layer are not taken into account. These degradations are taken into account by doing cross section analyses. The evaluation of work roll degradation is done by counting the crack length and the corrosion pits over the width of the sample. Illustration of corrosion and cracks after a degradation trial are reported in Figure $3 \mathrm{a}$ and $\mathrm{b}$. Figure 4 illustrates the corrosion factor and cumulated crack length for high chromium steel versus the cooling water composition.

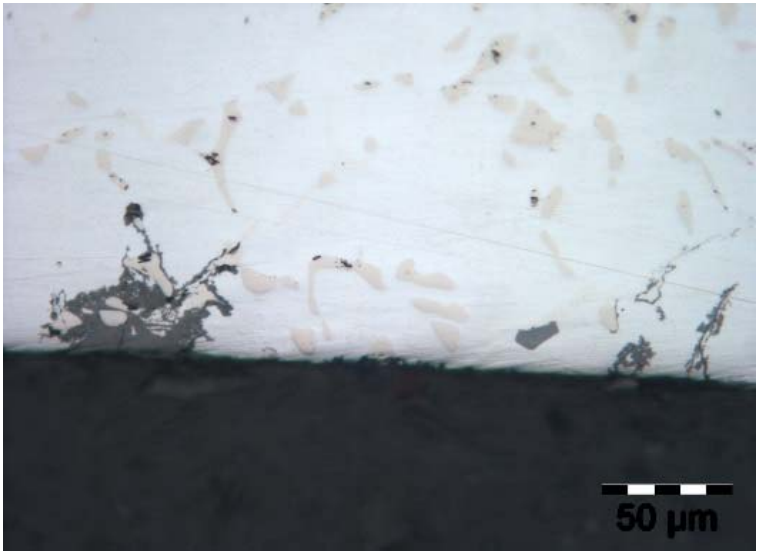

a)

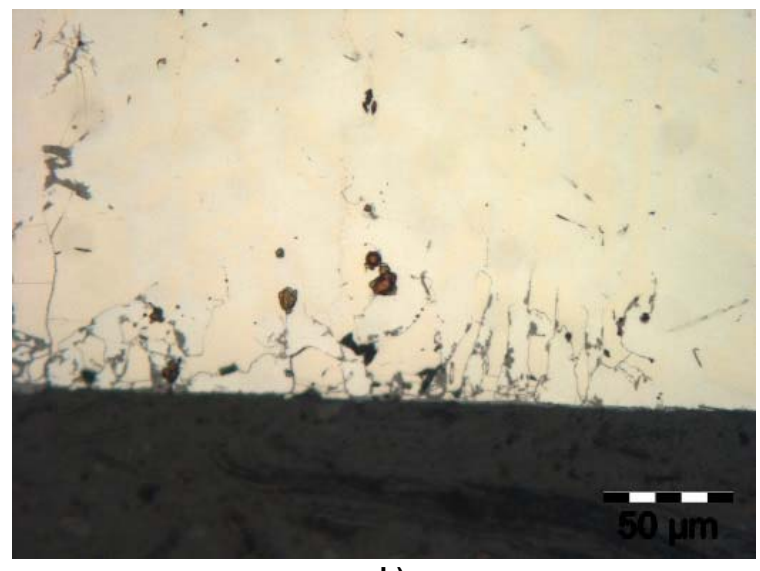

b)

Figure 3: illustration of a) corrosion and b) cracks on work roll samples after 2-disks rolling trial 


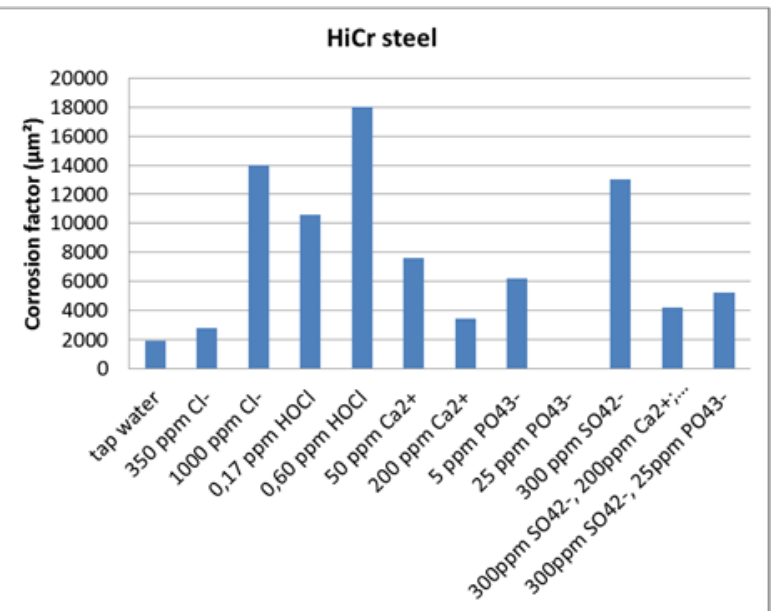

a)

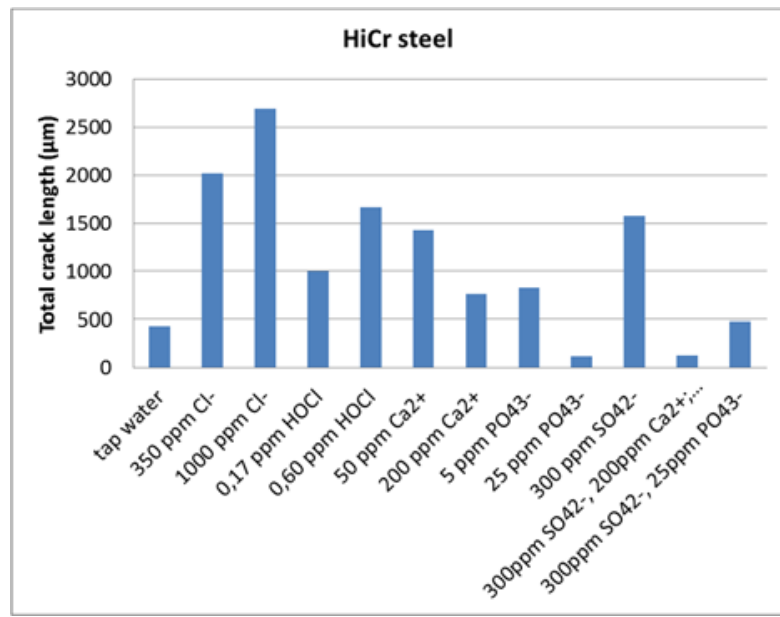

b)

Figure 4: Work roll degradation indexes vs cooling water composition for $\mathrm{HiCr}$ steel a) Corrosion factor b) Total crack length

It can be concluded from these trials that:

- increasing the chloride content from 350 to 1000 ppm increases drastically the corrosion factor $(x 5)$ and slightly the total crack length (1.35);

- the addition of free chlorine ( $\mathrm{HOCl}$ : bactericide) to $350 \mathrm{ppm} \mathrm{Cl}^{-}$is detrimental for the corrosion factor of work rolls but has a limited impact on the total crack length. This parameter is however certainly influenced by the removal of pieces of material by enhanced corrosion;

- the presence of sulphates also increases the corrosion factor of work roll materials;

- the addition of calcium at a concentration of 200 ppm has a beneficial impact on work roll degradation (similar corrosion factor but the total crack length is 2.5 times lower). On the other hand too much calcium has a detrimental impact on piping and spray headers in terms of clogging risks for instance.

- the presence of phosphate in addition to the $350 \mathrm{ppm} \mathrm{Cl}^{-}$of the cooling water decreases drastically work roll degradation. When present at a concentration of 25 ppm: no corrosion pits have been observed on the whole sample surface and only few cracks are present;

- the combination of calcium and phosphate ions has a cumulative impact on work roll degradation. When chloride and sulphates are present in water, the addition of $25 \mathrm{ppm} \mathrm{PO}_{4}{ }^{3-}$ is efficient to decrease work roll degradation. However the addition of $200 \mathrm{ppm}$ of calcium to this water decreases even more the degradation observed on the samples.

\subsection{Results of Cyclic Oxidation Trials}

The oxidation mechanisms of work rolls have been investigated for $\mathrm{HSS}, \mathrm{HiCr}$ iron and ICDP through cyclic oxidation trials. Parameters like the furnace temperature, cooling water composition, number of cycles and furnace atmosphere have been studied. This paper describes the oxidation mechanisms of HSS and compares the oxidation kinetics of HSS and ICDP materials.

The study of work rolls oxidation mechanisms was done with constant parameters (furnace temperature and atmosphere, water composition and temperature, duration of the cycles) and varying the amount of cycles. Figure 5 illustrates the cross section 
analyses on HSS after oxidation trials of 1, 5, 20 and 100 cycles. During the first cycle, a thin oxide layer is formed on the work roll surface (external oxidation). After 5 cycles, the external oxide layer continues to grow but an internal oxidation of the matrix starts. The internal oxide layer is discontinuous as only the matrix oxidises. Depending on the carbides composition and the humidity in the high temperature step, the difference in oxidation kinetics between carbides and matrix can vary from lower, similar or higher oxidation kinetics $[3,4,5]$. In the present study it was observed that the external oxide layer is thinner over carbides than over the matrix. When increasing the number of cycles (20 up to 100 cycles) both oxide layers (internal and external) continue to grow. Secondary carbides do not oxidise.
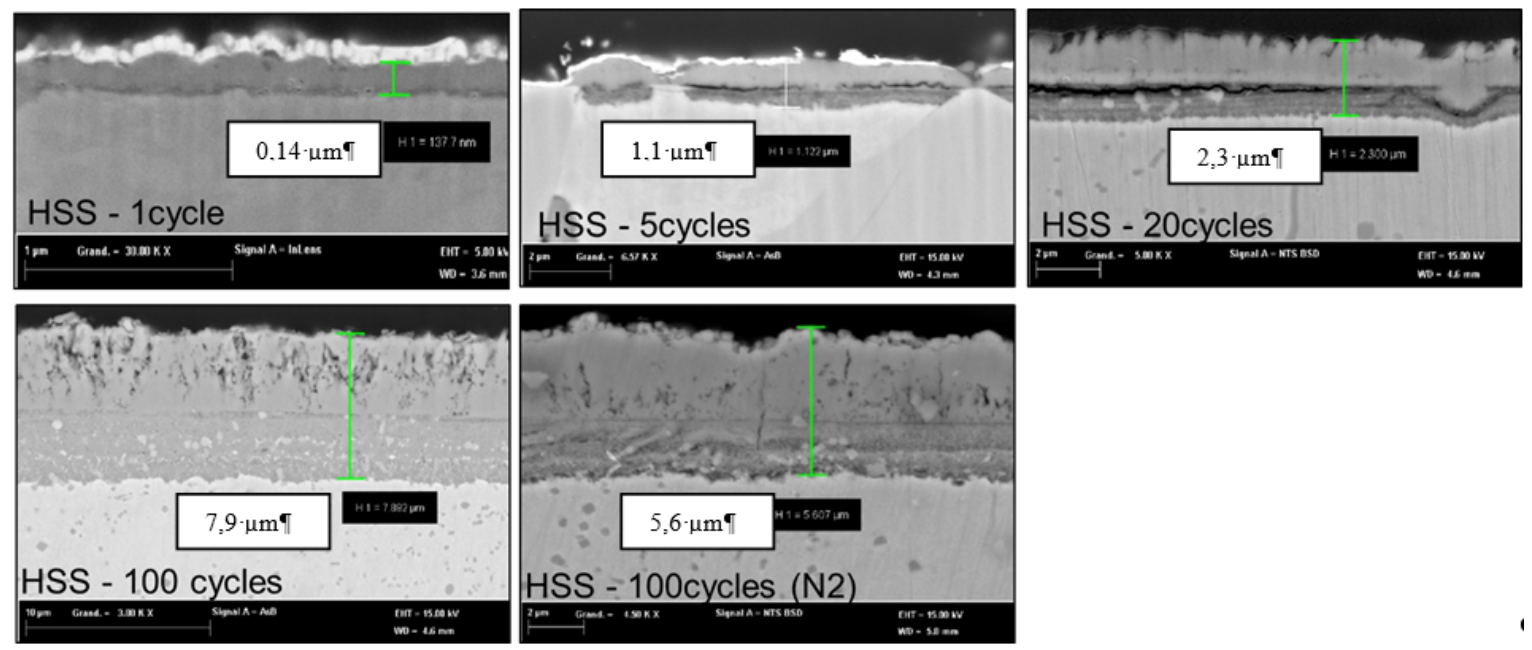

Figure 5: HSS cross section after oxidation tests (remark: magnifications are not constant)

It needs to be mentioned that in the roll gap, when the roll surface is in contact with the strip, only limited amounts of oxygen and humidity are present during the high temperature step. This could be reproduced by our cyclic oxidation tests with a nitrogen atmosphere in the high temperature phase. This stage at high temperature is also comparatively very short on one roll revolution. Cyclic oxidation trials were carried out with nitrogen instead of air for the high temperature step. As shown on the last picture of Figure 5 (HSS - 100 cycles N2), the oxide thickness is ony slightly thinner when no oxidising agent is present during the high temperature stage. This indicates that the high temperature step is not the dominant oxidation stage. The oxidation by cooling water seems thus the dominant mechanism for explaining the oxidation of work roll surface. The role of the high temperature step seems thus limited to anneal the oxide. Similar oxidation mechanisms were observed with ICDP and $\mathrm{HiCr}$ materials.

Oxidation kinetics of ICDP and HSS work roll materials have also been investigated and have enabled us to determine that ICDP oxidises faster in the early stages than HSS. As illustrated in Figure 6a, after 1 cycle the oxide layer on ICDP is two times thicker compared to HSS. This higher oxidation kinetic of ICDP is also observed after 5 and 20 cycles. When reaching 100 cycles, oxide layers on HSS and ICDP are similar. This means that an oxide layer is rapidly formed on ICDP after a few revolutions of the roll while HSS needs more time to oxidise. After 5 cycles, oxidation kinetic of HSS is almost linear with the number of cycles while ICPD has almost reached its maximum oxide thickness after 20 cycles. Compared to HSS, ICDP reaches rapidly a thick oxide layer which will not grow further. 
If we compare oxidations at $425^{\circ} \mathrm{C}$ (estimated contact temperature in rear finishing stands) and $600^{\circ} \mathrm{C}$ (estimated contact temperature in early finishing mill) it is observed that at $600^{\circ} \mathrm{C}$, the oxide thickness on both materials are similar while at $425^{\circ} \mathrm{C}$, the oxide layer on ICDP is two times thicker than on HSS.

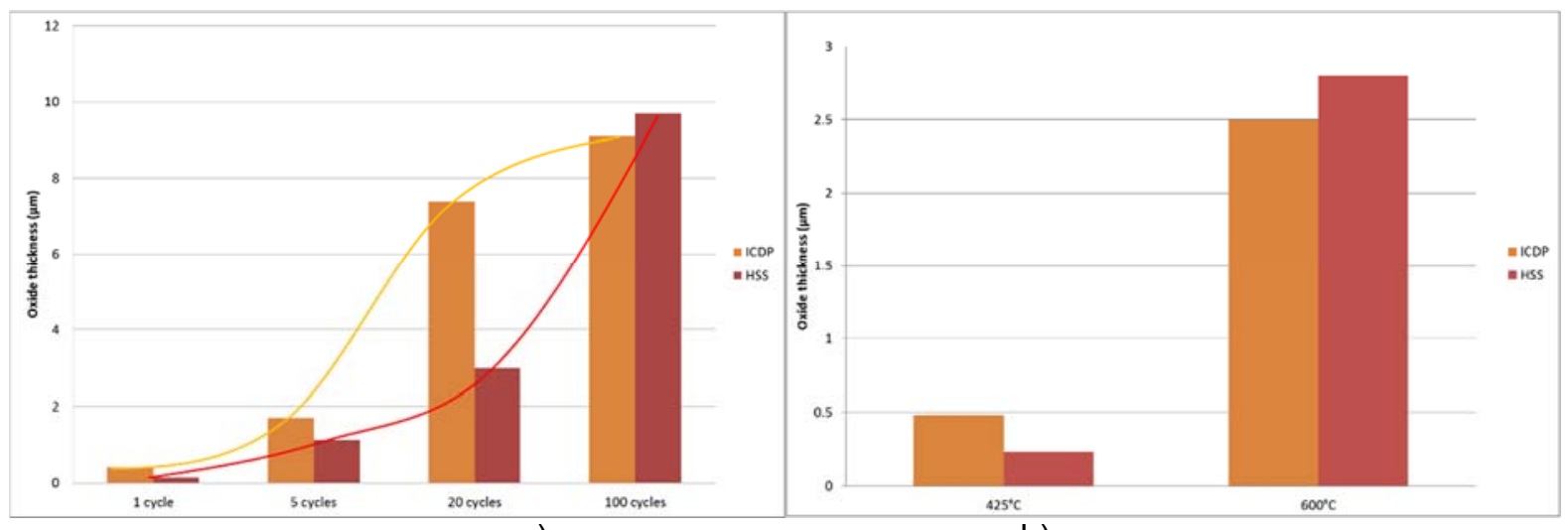

a)

b)

Figure 6: Oxidation of work roll materials a) vs number of cycles; b) vs temperature

Based on this study, we can conclude that:

- Oxidation of work roll materials is not ruled by the oxidation at high temperature. The formation of the oxide layer proceeds by oxidation by the contact with cooling water followed by an annealing of the oxide at high temperature:

0 an external oxide starts growing from the first revolution on;

0 during the next revolutions, the external oxide continues to grow and an internal oxidation of the matrix starts;

o both oxide layers continue to grow during the further revolutions of the roll in the mill

- The oxidation mechanisms of ICDP, HSS and HiCr iron are similar, only the kinetics vary between the grades;

o ICDP oxidises at lower temperature than HSS and requires less cycles to form a certain oxide thickness;

\section{CONCLUSIONS}

All the laboratory studies and worn work roll examinations lead over the past decade enabled an increased knowledge on work roll oxidation and corrosion/degradation.

Laboratory trials have proved that work roll oxidation and corrosion are highly dependent on the cooling water composition. Based on laboratory trials, oxidation and oxidation-corrosion of work rolls have been clarified:

- Oxidation of work rolls is ruled by the contact with cooling water followed by an annealing during the high temperature step.

- The impact of water composition has been proved to be a key parameter in work roll surface degradation.

- Oxidation of the matrix along crack tips is called corrosion.

- Although composition of work rolls can vary in wide ranges, oxidation mechanisms remains the same, only kinetics vary between work roll grades.

Cooling water impact on work roll oxidation and corrosion is thus a key parameter to be taken into account for the development of new work roll grades. 


\section{Acknowledgments}

Grateful acknowledgement to the Wallonia government for their financial contribution in research works.

\section{REFERENCES}

1 G. Walmag, H. Uijtdebroecks, "Mechanisms of work rolls degradation in HSM", Rolls4 Conference, Birmingham 2007,UK

2 G. Walmag \& al., "Development of new materials based on on-site and laboratory evaluation methods for understanding work roll surface degradation", Proceedings of the 2012 AISTech conference, United States of America, 2012

3 JP. Breyer, R.J. Skoczynski, G. Walmag, "IMPROVEMENT OF THE WORK ROLL PERFORMANCE ON 2050 MM HOT STRIP MILL AT ISCOR VANDERBIJLPARK", Proceedings of the conference SARUC 2000, Vanderblijpark Gauteng, South Africa, 2000

4 Q. Zhu, "A study of oxidation and wear on high speed steel roll material", Thesis University of Wollongong, 2012

$5 \quad \mathrm{H}-\mathrm{H}$. Kim \& al. "Oxidation Behaviour of High Speed Steels in Dry and Wet Atmospheres", ISIJ International, Vol. 43 No. 12, pp. 1983-1988, 2003

6 M. Pellizzari, A. Molinari, G. Straffelini, "Tribological behaviour of hot rolling rolls", Elsevier Wear 259, pp1281-1289, 2005 